\title{
¿Qué es políticamente posible en tiempos de globalización?
}

What is Politically Possible in Globalization Times?

\author{
Griselda Gutiérrez Castañeda \\ Universidad Nacional Autónoma de México \\ grix19@yahoo.com.mx
}

DOI: http://doi.org/10.15366/bp2019.20.010

Bajo Palabra. II Época. No20. Pgs: 181-198 
Este artículo ha sido escrito en el marco del Proyecto de Investigación "El desván de la razón: cultivo de las pasiones, identidades éticas y sociedades digitales”

(Proyecto PAIDESOC. FFI2017-82535-P).

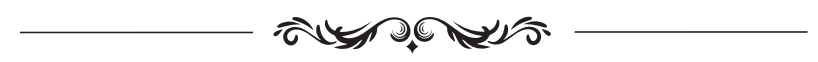

\section{Resumen}

Las tendencias de complejidad e indeterminación crecientes características a la globalización y agudizadas por las políticas económicas neoliberales, producen cambios en las dinámicas económicas del mercado mundial y efectos que trastocan los marcos institucionales jurídico-políticos de los estados. Desde dicho horizonte analizo: cómo estas transformaciones radicalizan las interrogantes sobre las posibilidades de inclusión o exclusión de los agentes sociales, la densidad de los efectos fragmentadores en la formación de identidades colectivas, y pondero las oportunidades o las restricciones de intervención política relevante, o si existe margen para la resistencia.

Palabras Clave: Globalización Inclusión/ Exclusión Fragmentación Desinstitucionalización Sujetos políticos.

\section{Abstract}

The growing tendencies of complexity and indeterminacy characteristic of globalization and exacerbated by neoliberal economic policies, produce changes in the economic dynamics of the world market and effects that disrupt the juridical-political institutional frameworks of the states. From this horizon I analyze: how these transformations radicalize the questions about the possibilities of inclusion or exclusion of social agents, the density of fragmenting effects on the formation of collective identities, and ponder the opportunities or constraints of relevant political intervention, or whether there is room for resistance.

Keywords: Globalization Inclusion / Exclusion Fragmentation Deinstitutionalization Political subjects. 
$\mathrm{E}$ $\mathrm{n}$ aras de esbozar posibles respuestas a las interrogantes enunciadas, a la par de examinar los efectos sistémicos que algunas de las tendencias definitorias de la globalización producen en los distintos ámbitos de la vida social, recurriré a la contrastación con algunos elementos del modelo del Estado de bienestar con el propósito de ponderar las relevantes diferencias entre las pautas de integración social y política empleadas por éste, respecto a los mecanismos que hoy día operan en los sistemas sociales, los cuales estructuran en un sentido sistémico la inserción de las y los agentes sociales en los distintos procesos y ámbitos funcionales, y con dicha base sopesar las oportunidades, las restricciones y los riesgos que se encaran en las sociedades actuales o las posibilidades de trascenderlos, social y políticamente hablando.

\section{De la centralidad al descentramiento del Estado}

HAN SIDO MÚLTIPLES Y SUSTENTADAS LAS CRíticas al modelo de organización democrático-liberal como posibilitador de oportunidades generalizadas, para el que las dimensiones del trabajo y de la política habrían de ser las vías por excelencia de afirmación de los sujetos sociales, son las críticas y las promesas incumplidas y, hoy día, al parecer incumplibles, las que como marco referencial permitieron explicar e inconformarse el que prevalecieran condiciones de inclusión precaria o de exclusión económico-social, así como de exclusiones significativas que han negado la condición de pactantes a anchas franjas de integrantes del orden político, por marcajes de clase, étnico-racial o de género.

Sin embargo, como marco referencial a la vez que nos permite colegir cómo las actuales formas de exclusión responden a una nueva problemática, nos da indicios de que la resistencia a abandonar las expectativas de sus promesas es porque la dimensión del trabajo y de la política son cruciales en el proceso de integración subjetivo, social y, desde luego, político.

Históricamente entre las funciones de construcción de orden por parte del Estado, las formas de integración política de una comunidad fueron decisivas, originalmente se basaron en lealtades nacionales, y en la consolidación de la representación simbólica del Estado-nación como encarnación del lazo común.

Importante resaltar que entre los criterios que le dieron sustento a la integración de los ordenamientos político-sociales occidentales modernos estaba la inclusión 
en términos de libertades y protección, cifrada en el carácter formal de la membresía jurídico-política, no obstante, la inclusión siempre se materializó en términos de oportunidades, que pueden ser de distinto tipo, pero de manera relevante en oportunidades económicas. Estas últimas, particularmente en el marco del diseño político liberal habrían consistido en la creación de regulaciones y mecanismos que garantizaran seguridad, justicia -en un sentido formal- y libertades, no así en el marco del diseño político democrático-liberal en el que la inclusión habría contemplado, al menos como proyecto, seguridad y justicia en términos sociales.

El gozne fundamental de la integración social habría sido la integración política en la figura del pacto como fictio iuris, definitoria tanto en un sentido simbólico como en el trazo del diseño institucional, al determinar como premisa el consentimiento de las partes, por la legitimidad que le insufla a quien conduce en términos de representante de esa voluntad general -con los consiguientes mecanismos para su expresión-; porque su lógica define las pautas de la comunicación política, en términos de la regulación de las formas de ejercicio del poder y de las políticas de provisión de protección y servicios; pero también, porque simboliza la integración de una comunidad nacional en un sentido político y cultural. Con dicha base la ciudadanía ha aglutinado pertenencia y derechos, sostenida conforme a criterios de adscripción (ius soli/ius sanguinis), y de forma emblemática conforme al criterio de consentimiento, convirtiendo la identificación con la comunidad política y la filiación con el Estado en un vínculo cívico. Una conexión civil que social y simbólicamente habría pautado formas de socialización, de pertenencia y la integración de los individuos conforme a roles, y en términos jurídico-políticos la delimitación de criterios de membresía; un marco de institucionalidad capaz de regular la comunicación política, dentro de cuyos linderos se habrían de negociar los niveles de responsabilidad para proveer bienestar, protección y alcance de los derechos, y el tipo de exigibilidad de las obligaciones, circunscritos a límites que funcionalmente preserven estabilidad y continuidad del ordenamiento.

Vayan estas breves notas como preámbulo para problematizar algunos de los ejes que configuran el nuevo horizonte socio-histórico.

La densidad de las transformaciones que hoy se experimentan como cristalización de un orden mundial globalizado conllevan cambios en todos los planos de la vida social, en lo concerniente a las dinámicas económicas del mercado mundial prevalece una intensificación de las interdependencias con base en formas de ejercicio del poder interregional y transcontinental, con el consiguiente desplazamiento del papel de los estados como unidades fundamentales del orden mundial; lo que va de la mano con cambios en la escala de prioridades, como es la ampliación de la extracción de beneficios para los corporativos globales respecto a la posibilidad 
de desarrollo de las economías nacionales y de desarrollo humano. La internacionalización de la producción y de los flujos financieros, que intensifican comercio, inversión y migración, tiene como uno de sus requisitos el contar con condiciones de flexibilidad que permiten traspasar las regulaciones nacionales y un efecto colateral de desregulación, no aleatorio sino sistemático.

El impulso de estos cambios genera una tendencia creciente de subsunción del subsistema político a la lógica de la economía, lo cual produce efectos que trastocan los marcos institucionales jurídico-políticos de los estados y sus dinámicas operativas y regulatorias, desdibujando el sentido y alcance de sus tradicionales atribuciones y competencias.

Entre los factores que explican la posibilidad y la relevancia que cobra el criterio de flexibilidad está la revolución en los recursos tecnológicos y comunicacionales que son clave en los procesos globalizadores, capaz de producir el desplazamiento del referente espacial a partir de una reconfiguración del referente temporal ${ }^{1}$, al dar lugar a interconexiones cuya velocidad y virtualidad traspasa fronteras. En particular se resaltan los efectos prácticos de la flexibilidad, de manera que en el discurso empresarial y en el político se valoran sus cualidades, como la apertura y capacidad de trascender restricciones que abren oportunidades y competitividad; pero existen otros efectos cuya relevancia es indiscutible, como la presión operativa que ejerce sobre las regulaciones jurídicas y procedimentales con consecuencias que mellan el funcionamiento institucional, dado que las formas regulatorias y procedimentales operan con temporalidades que hacen corto-circuito con el potencial y velocidad de tales tecnologías. La resultante es una tendencia a la desregulación que se vuelve fundamental en los procesos de interconexión económicos, políticos y jurídicos, tanto a nivel internacional como local. Es la apropiación de estos recursos por parte de políticas económicas neoliberales la que "institucionaliza" -a manera de oxímoron- la desregulación, al priorizar la lógica del mercado y reducir las políticas de intervención y regulación por parte del Estado, por cuanto la tensión con el marco de rutinas, normativas y procedimientos jurídicos establecidos, ejerce presión para una relajación o abierta fractura de los mismos, lo que lleva a la instauración de reformas legales altamente permisivas (de inversión, comercialización y laborales), o a la imposición de prácticas de abierta ilegalidad.

La conjunción de las dinámicas globalizadoras y las políticas económicas neoliberales, como las políticas de ajuste estructural, conllevan programas de repliegue por parte de los estados, en tanto restringen sus funciones a la mera conservación de la estabilidad y la complejidad del sistema social y producen a nivel sociológico

${ }^{1}$ Held, David, Modelos de democracia. Madrid, Ed. Alianza, 1996, pp. 380-381. 
efectos fragmentadores, al dejar a las y los agentes sociales expuestos a la lógica del mercado, o dejarlos a la deriva, ante la circunstancia de ser desplazadas/os, o indocumentadas/os.

El escenario de la globalización desde la teoría de sistemas de Luhman ${ }^{2}$ por ejemplo, parte de un código de interpretación del sistema social conforme a criterios de complejidad y diferenciación de los dominios funcionales del sistema, cuya lógica está marcada por procesos de homeostasis y autorreferencia, un modelo explicativo en el que la pérdida de centralidad de la política y sus instituciones se concreta en inflación del poder político, en pérdida de su función formadora de identidad, y en relación a lo que se habría denominado acción social y/o política, esta deviene en meros procesos funcionales de carácter adaptativo.

Tesis que se afianza al observar la operatividad de dos de los códigos funcionales del sistema político para la regulación social, como el de inclusión/exclusión y el de la relación asimétrica dominio/subordinación; en lo que concierne al segundo, como lo apunta el autor, tradicionalmente las iniciativas de acción pugnaron por recursos legales para regular la relación gobernantes-gobernados, más tarde ante problemas de inequidad las luchas se encaminaron por políticas distributivas, hoy día en escenarios de complejidad creciente -ante las tendencias de descentramiento e inflación de la política y en condiciones de indeterminación y escasez-, se acentúa el carácter autorreferente y autoproducido de los sistemas sociales; lo cual significa un desplazamiento de la intervención planificada y la conversión de la relación asimétrica en los términos decisiónlafectados, es decir, no importa qué instancia "decida", siempre habrá afectados. Y respecto al código inclusión/exclusión sólo se incluirán o atenderán las irritaciones capaces de producir efectos desestabilizadores. ${ }^{3}$

En términos socio-económicos las políticas de repliegue se traducen en el decaimiento de los niveles de bienestar, de reducción del rango y calidad de oportunidades de inclusión marcadas por la precariedad. En términos políticos ese repliegue del subsistema político confirma una lógica autorreferencial que se expresa en el abandono de sus funciones reguladoras y mediadoras entre las partes involucradas en las relaciones laborales, o de políticas de intervención compensatoria, así como en la ejecución de programas y decisiones que resultan ajenos a los requerimientos sociales de sus gobernados.

Económicamente la articulación de las tendencias de flexibilización, desregulación y movilidad de las inversiones contribuye a desplazar formas tradicionales de producción y privilegia la terciarización, y con ello la ampliación de formas

${ }^{2}$ Luhmann, Niklas y Raffaele De Giorgi, Teoría de la sociedad. Guadalajara, U de G/UIA/ITESO, 1993.

3 Zolo, Danilo, Democracia y complejidad. Un enfoque realista. $1^{\text {a }}$ ed. en castellano, Trad. Horacio Pons, Ed. Nueva Visión, Buenos Aires, 1994. 
maquiladoras y del sector servicios. Que las formas de empleo no se apeguen a regulaciones laborales, incluyendo el respeto a los derechos correspondientes, propicia un deslizamiento entre "trabajo" y "servicio" a manera de una tendencia de "deslaborización del trabajo", como atinadamente la caracteriza Yánez ${ }^{4}$, ya que prevalecen formas de subcontratación, un trabajo que alcanza espacios informales como el doméstico o el ambulantaje en la vía pública, que al no mediar formas regulares de contratación se traduce en que no se adquiere el estatus de asalariada/o, por lo que el vínculo cobra la tesitura de una relación comercial en que se entregan servicios.

Si bien el modelo postindustrial no ha diluido por entero modelos organizativos tradicionalistas, o los característicos a las sociedades industriales, lo que se observa es un traslape con los actuales esquemas, de manera que las nuevas tendencias estimulan el desplazamiento de las modalidades y la centralidad de dos ejes de la organización y la inclusión social, el del trabajo y el de la política, en la modalidad de trabajo productivo y en el de la política adscrita al Estado-nación, tesis sostenida por Garretón con quien coincido 5 . Típicamente el trabajo productivo como estructurador de la existencia no sólo ha cumplido una función de integración social, a la que más adelante me referiré, sino también, como lo destaca el autor, ha dado lugar históricamente a la codificación política de iniciativas de movilización, organización y comunicación encaminadas a demandar inclusión y redistribución; en su lugar, lo que hoy presenciamos es una creciente dispersión de iniciativas de organización y la desarticulación de los actores colectivos tradicionales -como organizaciones sindicales, un debilitamiento sustancial del movimiento laboral y de una cultura de la clase trabajadora-, con lo cual se observa la tendencia a encarar escenarios adversos de manera aislada e individual, al estar privados de esos marcos organizativos de referencia y de dilución de marcos político institucionales de contención.

\section{Políticas de integración vs Políticas de inserción}

LA CONFLUENCIA DE LOS FACTORES MENCIONADOS y sus consecuencias sobre la afectación que acarrean en las condiciones de incorporación de los agentes en estos escenarios, explica que los debates prácticos y teóricos giren entre la noción de ex-

\footnotetext{
${ }^{4}$ Yáńez, Sonia, "La flexibilidad laboral como nuevo eje de la producción y la reproducción”, en Todaro, Rosalba y Yáñez, Sonia (editoras) El trabajo se transforma. Relaciones de producción y relaciones de género. Santiago de Chile: Ed. Centro de Estudios de la Mujer, 2004, pp. 85 y 103.

5 Garretón, Manuel Antonio, “Las transformaciones de la acción colectiva en América Latina”, en Agustín Martínez (coordinador) Cultura politica. Partidos y transformaciones en América Latina, Caracas, CLACSO, 1997.
} 
pulsión y la de exclusión social-entre otras variantes ${ }^{6}$. De ahí la importancia de que nos detengamos en la relación del trabajo con la dinámica social, con base en algunas líneas que aportan las investigaciones teóricas y de campo desde las disciplinas sociales, las cuales confluyen en la centralidad de dicha relación y destacan cómo el trabajo "es un soporte privilegiado de inscripción en la estructura social" ${ }^{7}$, lo mismo en el proceso de incorporación y formación subjetiva, en el desarrollo de formas de apego y de reconocimiento de las normas y en el significado de lo público; como también coinciden en los efectos disruptores de la precarización y de la expulsión del mundo laboral, tal como lo establecieron las reflexiones pioneras de Durkheim.

Bajo la consideración histórica de los procesos de modernización crecientes Robert Castel examina no sólo cómo el proceso de integración se sustenta en el eje del trabajo, en la red relacional educativa y familiar y, de manera fundamental, en el vínculo con la esfera institucional, que además de aportar regulaciones generales, sustenta un sistema de derechos objetivos; de ahí la atención que le concede a la gestión política ante escenarios de crisis, como ha sido la intervención del Estado históricamente hablando, por ejemplo, ante las condiciones de depresión y la opción por otras alternativas ideológico-políticas en el periodo de entre guerras y de la posguerra, intervención esta última, que se plasmó en el Estado social o benefactor. Que como golpe político significaba "la disolución de esa alternativa revolucionaria, y la redistribución de la conflictividad social según un modelo diferente del de la sociedad de clases: la sociedad salarial" ${ }^{8}$ y como estrategia articulaba la política, la economía y lo social, al garantizar de manera generalizada protección social, para lo cual era menester el pilotaje de la economía, manteniendo equilibrio, impulsando desarrollo y estableciendo compromisos de distinto orden, de inversión y desarrollo con los asociados económicos, y con el resto de la sociedad "pacto de trabajo, pacto de ciudadanía"; un modelo de cohesión social basado en la noción de integración, lo que significa que el trabajo conforme al criterio de "utilidad social" enlazaría desarrollo personal, pertenencia grupal e inclusión institucional, en el que el trabajador se convertía en ciudadano de un sistema de derechos sociales, desde luego una integración socio-política con su contraparte económica, la de ser consumidor.

Lejos de trazar una imagen acrítica o ingenua de dicho modelo -que siempre estuvo lejos de generalizar oportunidades económicas, integración social y parti-

\footnotetext{
${ }^{6}$ Sassen y Saraví, respectivamente. Ver Sassen, Saskia, Expulsiones. Brutalidad y complejidad en la economía global. 1a. ed. Traducción Strella Mastrangelo, ed. Katz, Buenos Aires, 2015; y Saraví, Gonzálo Transiciones vulnerables: Juventud, desigualdad y exclusión en México. México, Ed. CIESAS, 2009.

${ }^{7}$ Castel, Robert, La metamorfosis de la cuestión social. Una crónica del salariado. Barcelona, Paidós, 1995, p. 95.

${ }^{8}$ Castel Op. Cit. P. 302

9 Ibid. P. 317
} 
cipación política, lo que explica las innumerables luchas por inclusión-, lo que interesa es contrastar qué implica una política de integración respecto a una política de inserción por sus efectos en el plano de la cohesión social y en una tendencia a la desinstitucionalización de la política.

Como bien apuntó Dahrendorf ${ }^{10}$, entre otras muchas voces, los costos y los defectos del Estado de bienestar que en la perspectiva de sus críticos justificaban desmantelarle, no parecen haber calculado el efecto diluyente en el plano social, subjetivo y político, como a la postre tampoco parecen sopesarse los daños irreparables a la cohesión social que se siguen profundizando, al persistir la prioridad de la competitividad en el mercado mundial pese a los "daños colaterales".

Pensar en la política de inserción nos remite al debate que cobra especial relieve en el campo de las ciencias sociales, como antes mencioné, a propósito de dar cuenta de bajo qué condiciones se incorporan los agentes sociales en los nuevos escenarios, sea que se parta de la teoría de sistemas o de los estudios cualitativos que teorizan la nueva cuestión social -o quienes articulan ambas perspectivas-; conforme al primer enfoque, la atención se centra en los mecanismos que estructuran en un sentido sistémico la inserción de las y los agentes sociales en los distintos procesos y ámbitos funcionales, que al partir de la lógica homeostásica del sistema social dan cuenta de su verdadero significado, de manera que: la inserción de los agentes sociales es conforme a tendencias funcionales que preseleccionan posibilidades, limitan alternativas y sobredeterminan la expectativa social, generando mecanismos en que la frustración se traduce en aprendizaje y el desengańo en conductas adaptativas ${ }^{11}$, todo ello dentro de un margen que puede ir de la expulsión ${ }^{12}$, a distintas formas de exclusión, o la inserción funcional.

En el segundo enfoque, se busca interpretar el abanico de los casos extremos de privación y marginalidad de algunos grupos, junto con la de amplios sectores sociales cuya situación es de inclusión desfavorable, ya que pese a carencias y obstáculos buscan formas de incorporación en el mercado laboral; desfavorable por efecto de la acumulación de desventajas y la situación de vulnerabilidad que acarrea. Es una perspectiva teórico conceptual que enfatiza la dimensión social y la subjetiva, cuyo rendimiento teórico es de interés porque además de registrar los casos extremos de exclusión, como argumenta Saraví, intenta comprender las nuevas formas de configuración social con base en las modalidades contemporáneas de desigualdad, diferenciación y polarización. ${ }^{13}$

\footnotetext{
${ }_{10}$ Dahrendorf, Ralf, Quadrare il cerchio ieri e oggi. Bari, Laterza Editori, 2009.

11 Ver Luhmann y De Giorgi op. cit., y Zolo op. cit.

12 Ver Sassen op. cit.

13 Saraví op. cit. P. 24
} 
Con lo cual, en las investigaciones de campo, no sólo se puede comprobar que el mercado de trabajo se ha convertido hoy día en uno de los principales generadores de vulnerabilidad y exclusión social -lo mismo que el sistema de educación formal, con sus especificidades-, al producir una fractura en la integración social y, a su vez, condicionar fragmentación social ${ }^{14}$. El punto a destacar es que aun cuando en estas investigaciones hay interés en "reconocer el interjuego entre estructura y agencia" ${ }^{15}$, considero que ello no reduce el carácter de inserción conforme a posibilidades preseleccionadas funcionalmente, acorde con la precarización social y laboral, la reducción de oportunidades, y su baja calidad, lo que incrementa la vulnerabilidad, el desempleo y con ello la desafiliación.

Dentro de esta misma línea teórica considero clave la noción de desafiliación propuesta por Castel, porque nos da herramientas para aproximarnos a la articulación entre la fractura de la integración sujeto-sociedad, la fragmentación social y el distanciamiento con la política y sus cauces institucionales; al respecto el autor se decanta por el término desafiliación más que por el de exclusión:

La exclusión es inmóvil. Designa un estado o más bien, estados de privación. Pero la simple constatación de las carencias no permite captar los procesos que las generan. Hablar de desafiliación en cambio, no es confirmar una ruptura, sino retrazar un recorrido. El concepto pertenece al mismo campo semántico que la disociación, la descalificación o la invalidación social... en esta perspectiva, la zona de vulnerabilidad ocupará una posición estratégica. Reducida o controlada, ella permite la estabilidad de la estructura social... Al contrario, abierta y en extensión, tal como es aparentemente hoy día, la zona de vulnerabilidad alimenta las turbulencias que debilitan las situaciones logradas y deshacen las estabilidades aseguradas... ${ }^{16}$

El que social e individualmente se tenga que enfrentar la precariedad por condiciones de inestabilidad, bajos salarios y empleos miserables o el desempleo, como bien señala Zolo, a lo que da lugar es a hacerse cargo de una cuota más alta de decepción, a estar ocupados ante la frustración en restructurar expectativas, a generar estrategias de adaptación a los nuevos escenarios, y a sentirse ajenos a la política. Una distancia que se puede manifestar ya sea en una falta de tiempo y atención -ocupados en la sobrevivencia diaria-, en escepticismo y desencanto, y/o en enojo social respecto a la política y el sistema político en su conjunto.

\footnotetext{
14 Bayón, Ma. Cristina y Gonzalo Saraví, "De la acumulación de desventajas a la fractura social. 'Nueva’ pobreza estructural en Buenos Aires" en Gonzalo Saraví (editor) De la pobreza a la exclusión: continuidades y rupturas de la cuestión social en América Latina. Buenos Aires, Prometeo Libros, 2007

15 Saraví op. cit.

16 Castel op. cit. P. 14
} 
Aun cuando Castel amplía el radio de aplicación del concepto de desafiliación a distintas instancias sociales, me importa retomarlo por sus implicaciones en el plano político, conforme a su definición "La 'desafiliación' no necesariamente equivale a una ausencia completa de vínculos, sino a la ausencia de inscripción del sujeto en estructuras dadoras de sentido" ${ }^{17}$. Como se apuntó anteriormente, una de las formas de cohesión social que desarrolló el Estado benefactor fue bajo el marco que posibilitaba la ciudadanía social, lo que, con todo y sus limitantes, implicó un pacto de lealtades recíprocas, y en el que los canales de la comunicación política no estaban clausurados al dar espacio a la representación de intereses divergentes, incluyendo la formación de organizaciones colectivas y formas de interlocución para encauzar los conflictos y las negociaciones a través de los canales institucionales. En suma, la posibilidad de un vínculo institucional con el reconocimiento bidireccional, vale decir, apego y confianza a un orden instituido, por un lado, y el ser parte reconocida en calidad de socio del pacto, por el otro. Sin desconocer el sesgo utilitario de la ciudadanía que ese modelo prohijó, el intercambio posibilitaba otorgarle un sentido a lo colectivo, a la pertenencia, al marco institucional y a una cierta construcción de la esfera pública.

Entre los múltiples registros llevados a cabo en diversas regiones, cuyos países tienen muy disímbolos niveles de desarrollo socio-económico, como de consolidación institucional, no sólo se da cuenta de cómo la precariedad social prevaleciente ha generado cambios sustanciales, por las dificultades que encaran los agentes individuales y amplios estratos sociales para encontrar un lugar propio, involucrarse y sentirse parte de la sociedad, al experimentar injusticia y/o carencia de reconocimiento social, por la condición desventajosa de inserción o la abierta exclusión; lo cual genera insatisfacción con la sociedad y con las instituciones, con las políticas sociales y con la democracia misma, e incluso el vivir como remotas a la política y a las instituciones públicas ${ }^{18}$. Pero también se registra, un creciente desafecto con las formas democráticas de gobierno y profundo escepticismo hacia las instituciones liberales, expresadas en alejamiento de los partidos políticos, de las instituciones representativas e incluso hacia los derechos de las minorías, lo cual se interpreta en términos de profundos riesgos de "desconsolidación democrática” ${ }^{19}$.

17 Ibid. P. 349. Las negritas son nuestras.

18 Ver Informe 2017 Latinbarómetro; Social Precarity and Social Integration. Reporte escrito por Duncan Gallie and Serge Paugam. For the European Commission Directorate-General Employment Eurobarometer 56.1 October 2002.

19 Ver Foa, Roberto S. and Yaisha Mounk, "The Danger of Desconsolidation". Journal of Democracy. July 2016, Vol 27, No. 3.; y "The Sings of Desconsolidatión”. Journal of Democracy. January 2017, Vol. 28, No. 1 


\section{¿Qué es políticamente posible ante tendencias de desinstitucionalización?}

FRENTE A ESTOS RIESGOS, cuando un autor como Dahrendorf se pregunta “¿Por qué no existe un movimiento de grandes dimensiones que defienda a la sociedad civil? ¿Uno equivalente al movimiento socialista de fines del mil ochocientos y principios del mil novecientos?" ${ }^{20}$. Su respuesta confluye con otras voces que consideramos que no puede haber algo equivalente porque se ha transformado tanto la sociedad civil como la naturaleza del conflicto social, porque hoy día más que conflictos de clase, lo que se enfrenta son conflictos sistémicos como la pobreza, el desempleo y la violencia.

Por ello es menester hacerse cargo de tendencias como el que la interlocución con el Estado como referente de demandas enfrente un debilitamiento o dilución, porque ello se traduce en déficit de representación, cuyos efectos políticos implican una fractura del pacto ciudadano-Estado, que genera consecuencias en dos planos, en el de los gobernados su expresión es la pérdida del vínculo cívico, ante la experiencia de que los cauces de la comunicación política son inoperantes y están agotados, de que son afectados y meros observadores del curso de las decisiones políticas; desde el plano del subsistema político el efecto es una "desinstitucionalización" ${ }^{21}$, vale decir, la pérdida de su capacidad política de estructurar formas de identidad y de integración de comunidad política. Respecto al primer punto, se puede afirmar que se acentúa la desvinculación de los agentes respecto a los marcos objetivos que socialmente han estructurado su existencia, sea por el desplazamiento de la centralidad del trabajo y de la escuela como instancias de integración y de movilidad social, y, otro tanto, respecto a las organizaciones colectivas como instancias de pertenencia, comunicación y participación política; o en el extremo, porque el contacto con ese "mundo 'oficial" " está bloqueado para amplios sectores, que no han tenido ni tendrán acceso al mundo laboral, al escolar ni vinculación con la comunidad política ${ }^{22}$.

Y respecto a la pérdida de capacidad de integración de comunidad política, el que se acentúen en el ámbito social las condiciones de vulnerabilidad y la experiencia de incertidumbre hacen aparecer a la política, al sistema de partidos y a las instituciones estatales como algo ajeno y/o como instancias insuficientes o impotentes para contrarrestar o afrontar estas adversidades, al punto que se acrecientan conductas de desapego a las formas tradicionales de socialización e integración política que

20 Dahrendorf Op. Cit. P. 23

21 Ver Santiago, José, "La estructura social a la luz de las nuevas sociologías del individuo" en Revista Española de Investigación Social, No. 149, Enero-Marzo 2015, Madrid; y Zolo Op. Cit.

22 Dahrendorf Ibid. 
contribuyen a la dilución de la esfera pública. Desde el marco del subsistema político el problema puede ser una cuestión de gobernabilidad, pero desde el plano de los gobernados la problemática adquiere mayor densidad porque la transformación/ dilución de la comunicación política, va de la mano con el debilitamiento de las decisiones vinculantes y el no apego a cauces institucionales, producto de prácticas flexibles y desreguladas con las que las instancias oficiales dan cauce a formas permisivas y déficits de regularidad, certidumbre y legalidad; que al cabo repercuten en la calidad de las funciones protectoras y vinculantes que son responsabilidad de las instituciones y cuyas consecuencias afectan a los diversos ámbitos de la vida social.

Ese tipo de prácticas condicionadas por las tendencias sistémicas y por las presiones de los bloques de interés, hace que en el plano institucional se puedan constatar indicios de que numerosos dominios de autoridad se debilitan y fragmentan, por falta de apego a la normatividad, pero también por corrupción e impunidad, con lo que se acrecientan los riesgos de desestabilización política y social de distinta envergadura. El debilitamiento de las instituciones y de su autoridad invita a que socialmente prosperen conductas de desapego a las normas, y de impunidad al constatar que la ilegalidad forma parte del entorno; todo ello contribuye a acrecentar desconfianza, así como inseguridad, lo cual genera escepticismo y apatía respecto a conducirse por los cauces institucionales, pero también deriva en formas extremas como son los fenómenos desbordados de delincuencia y violencia que nos asuelan, por cuanto la experiencia de la exclusión, de ser prescindibles y la de la ineficacia o ruptura de los marcos y las reglas que nos contienen y nos limitan no puede más que traducirse en formas antisociales y violentas.

Por ello la insistencia en las consecuencias de la ausencia y/o la ineficacia de la función integradora de los marcos y las reglas políticas, ya que repercuten tanto en la función de autoridad y en la legitimidad de las instituciones y sus representantes, como en escenarios de fragmentación social que muestran el debilitamiento de las redes de socialización y de pertenencia social, lo que se manifiesta en mayores grados de polarización y de inseguridad.

A nivel internacional hay regiones en las que se agudiza la debilidad de recursos como el derecho por parte del sistema político para encarar los peligros de desintegración social, en tanto que el debilitamiento del recurso político de la deliberación para la formación institucionalizada de la voluntad y de la opinión, prácticamente es una tendencia generalizada, y no porque procedimentalmente deje de cumplirse el ritual, sino por el desafecto hacia la política; ya que se puede constatar que en un sentido práctico surgen justificadas dudas sobre la relevancia de cualquier iniciativa de participación, por cuanto las actuales tendencias parecen imponer una dinámica en la que la acción, la iniciativa, la intencionalidad o las pretensiones de control, 
tanto práctico como político, tienden a carecer de eficacia o incluso sentido, al no incidir en las agendas de manera que se traduzcan en decisiones políticas, ni repercutir en la dinámica del sistema.

No obstante, el clima de distanciamiento y desencanto generalizado por la política está lejos de implicar el vaciamiento de dicho espacio, a manera de un páramo, entre otras razones porque las fuentes de conflictividad están abiertas y se multiplican a la vez que se diversifican, es un espacio, como reconoce Dahrendorf, en el que "no hay una razón única de lucha que unifique, ni enemigo específico a confrontar [e inclusive], no hay sentido de pertenencia ni de compromiso social" ${ }^{23}$; ello explicaría la diversidad de conflictos, de reacciones y la proliferación de presencias en el plano social y político, diversidad que más que permitir una lectura optimista considerándoles expresión de pluralismo, lo que nos entrega es un mapa signado por la fragmentación y la desarticulación.

Entre las múltiples presencias ciertamente, están aquellas que capitalizan recursos materiales y de conocimiento en sus estrategias organizativas y que a la vez se proponen revitalizar y resignificar la política, pero que ni por su número ni por su incidencia permitirían desatender el hecho de la prevalencia de aquellos sectores ocupados en generar estrategias de sobrevivencia, políticamente pasivos o cuya aparición coyuntural es desorganizada y defensiva, porque son presencias abrumadoramente mayoritarias.

A su vez se registran presencias como movimientos sociales por derechos territoriales o étnicos con distintos grados de articulación. Así como aquellas alejadas de las formas tradicionales de integración política que tienden a orientarse por vías simbólicas y expresivas a fin de explorar y afirmar identidad de manera autorreferente, o en su caso generar relaciones solidarias, y grupos por afiliación con temas de la esfera vital o cotidiana, así como por identidad adscriptiva (etaria, sexual, religiosa, etcétera); grupos de carácter civil como las ONG y OSC con grados diversos de capacidad organizacional y expertise, conforme a agendas temáticas como derechos humanos, de género, ambientalistas, pacifistas, entre otras; además de grupos en calidad de actores transnacionales como los movimientos anti-globalistas; sin descontar presencias extrainstitucionales como los poderes fácticos.

No es fácil hacer un diagnóstico abarcante de lo que significa en términos políticos esta diversidad, pero me arriesgaría a sostener que políticamente hablando lo mismo en las expresiones que declaradamente son producto de iniciativas, que en las que obedecen a formas reactivas, lejos de ser plasmación del valor puro de la agencia y la creatividad e innovación, al parecer son expresiones que más que

23 Ibidem. P. 12 
sustraerse, responden a las precondiciones funcionales que preseleccionan las posibilidades y las alternativas, lo que en alguna medida quedaría confirmado por la diversidad, la fragmentación, y el tono de las movilizaciones tendencialmente dispersas y efímeras. Además de los casos de sectores especialmente desfavorecidos a los que se hizo referencia anteriormente, podemos pensar en distintos fenómenos que convalidan la tesis anterior, sería el caso de algunos de los movimientos cuya forma es la protesta, la manifestación (demonstration), cuyos vínculos son virtuales y de carácter simbólico, frente a los cuales no podríamos menos que darle la razón al diagnóstico de Luhmann, en el sentido de que son una suerte de efecto residual del propio sistema, que harían la función de observadores de la sociedad misma, con base en sus consecuencias, debido a que "No son organizaciones en tanto no organizan decisiones, sino motivos, commintments, vínculos..." 24; susceptibles de considerarles en algún sentido como expresión de resistencias, pero que si no generan estrategias de organización y continuidad se diluyen. Pero también sería el caso de aquellos movimientos cuyo principio de definición se sustenta en el repunte de las identidades culturales antes mencionadas, que como diagnostica Manuel Castells ${ }^{25}$ ante la globalización y la crisis de las instituciones del Estado-nación, son movimientos que contraponen formas anti-sistema que destruyen la legitimidad del Estado como fuente de sentido, situación que no parece fácilmente reversible.

Como parte de esta diversidad de expresiones estaría el recurso de las nuevas tecnologías de comunicación por las que se apuesta como una nueva forma de hacer política, que puede ser una vía para vincular las distintas presencias que hemos enumerado, recurso en el que se depositan grandes expectativas de democratización y solidaridad, además de la virtud de estar a tono con el cariz transnacional y de comunicación en red de un mundo globalizado; sin menospreciar su potencial, tendríamos que considerar los retos que la propia lógica del medio plantea a estas nuevas formas de acción colectiva, su capacidad de incorporar innumerables voces puede más que ser expresión de pluralismo volverle dispersa y fragmentaria, los recursos simbólicos y de interpelación diluirse en su virtualidad antes que condensarse en logros objetivos, y su apertura plasmarse en falta de controles, responsabilidad, transparencia y democracia.

Pero sobre todo me permitiría a manera de conclusión provisional considerar que, entre algunas de las expresiones referidas si bien pueden ser testimonio de que hay margen para la resistencia, la posibilidad de generar intervenciones políticas de alguna relevancia en términos de organización y continuidad, exige hacer política,

${ }^{24}$ Luhmann y De Giorgi Op. Cit. P. 376

25 Castells, Manuel, Globalización, Identidad y Estado en América Latina. Santiago de Chile, Temas de Desarrollo Humano Sustentable, PNUD, 1999, p. 8. 
diseñar formas de articulación política, darse a la tarea de construcción de equivalencias para conformar frentes de acción ${ }^{26}$; y como parte de ese trabajo político, sin desmedro de la autonomía de los agentes colectivos, ineludiblemente exige la rearticulación e interlocución con el Estado y sus instituciones que, con todo y la crisis que atraviesa, requiere ser reconfigurado y fortalecido como la única plataforma hasta ahora conocida para una posible reestructuración de cohesión e integración social, y más aún en sociedades masivas y complejas.

${ }^{26}$ Acorde con las propuestas formuladas por Laclau y Mouffe. Ver Laclau, Ernesto y Chantal Mouffe, Hegemonía y estrategia socialista. Hacia una radicalización de la democracia. Madrid, S. XXI, 1987. 


\section{ReferenCias Bibliográficas}

Bayón, Ma. Cristina y Gonzalo Saraví, "De la acumulación de desventajas a la fractura social. 'Nueva' pobreza estructural en Buenos Aires" en Gonzalo Saraví (editor) De la pobreza a la exclusión: continuidades y rupturas de la cuestión social en América Latina. Buenos Aires, Prometeo Libros, 2007. Pp. 55-95.

CAstel, Robert, La metamorfosis de la cuestión social. Una crónica del salariado. Barcelona, Paidós, 1995.

Castells, Manuel, Globalización, Identidad y Estado en América Latina. Santiago de Chile, Temas de Desarrollo Humano Sustentable, PNUD.

http://desarrollohumano.cl/idh/download/Idyest.pdf

Dahrendorf, Ralf, Quadrare il cerchio. Ieri e oggi. Bari, Laterza Editori, 2009.

Roldán, Concha, Brauer, Daniel and Rohbeck, Johannes (eds.), Philosophy and Globalisation, Walter de Gruyter, Berlin, 2018.

Foa, Roberto S. and Yaisha Mounk, "The Danger of Desconsolidation". Journal of Democracy. July 2016, Vol 27, No. 3. https://www.journalofdemocracy. org/.../Foa\%26Mounk-27-3.pdf

— "The Sings of Desconsolidatión”. Journal of Democracy. January 2017, Vol. 28, No. 1. https://www.journalofdemocracy.org/article/signs-deconsolidation

Garretón, Manuel Antonio, "Las transformaciones de la acción colectiva en América Latina”, en Agustín Martínez (coordinador) Cultura política. Partidos y transformaciones en América Latina, Caracas, CLACSO, 1997.

Held, David, Modelos de democracia. Madrid, Ed. Alianza, 1996.

Informe 2017 Latinbarómetro www.latinobarometro.org/LATDocs/F00006433 -InfLatinobarometro2017.pdf

Social Precarity and Social Integration. Reporte escrito por Duncan Gallie and Serge Paugam. For the European Commission Directorate-General Employment Eurobarometer 56.1 October 2002. ec.europa.eu/employment_social/ soc-prot/soc-incl/eurobarometer_en.pdf

Jacobson, David, Rights Across Borders. Immigration and the Decline of Citizenship. London, Ed. The Johns Hopkins University Press, 1997.

Laclau, Ernesto y Chantal Mouffe, Hegemonia y estrategia socialista. Hacia una radicalización de la democracia. Madrid, S. XXI, 1987. 
Luhmann, Niklas y Raffaele De Giorgi, Teoría de la sociedad. Guadalajara, U de G/UIA/ITESO, 1993.

SANTIAGo, José, "La estructura social a la luz de las nuevas sociologías del individuo" en Revista Española de Investigación Social, No. 149, Enero-Marzo 2015, pp. 131-151, Madrid.

Saraví, Gonzálo, Transiciones vulnerables: Juventud, desigualdad y exclusión en México. México, Ed. CIESAS, 2009.

SASSEN, SaSkia, Expulsiones. Brutalidad y complejidad en la economía global. 1a. ed. Traducción Strella Mastrangelo, ed. Katz, Buenos Aires, 2015.

YÁŃEz, Sonia, "La flexibilidad laboral como nuevo eje de la producción y la reproducción”, en Todaro, Rosalba y Yánez, Sonia (editoras) El trabajo se transforma. Relaciones de producción y relaciones de género. Santiago de Chile: Ed. Centro de Estudios de la Mujer, 2004.

Zolo, Danilo, Democracia y complejidad. Un enfoque realista. $1^{\text {a }}$ ed. en castellano, Trad. Horacio Pons, Ed. Nueva Visión, Buenos Aires, 1994.

DOI: http://doi.org/10.15366/bp2019.20.010

Bajo Palabra. II Época. No20. Pgs: 181-198 